\title{
EL TEATRO DE PÍO BAROJA: UNA CURIOSIDAD
}

Como nunca creí que fuera a representar nada mío, hice la prueba de pegar ligeramente en el manuscrito dos o tres páginas del comienzo y otras dos o tres del final.

Palencia me dijo todas esas vulgaridades que se dicen a los principiantes. Que no tenía experiencia del teatro... palabrería pura.

A los cuatro o cinco meses vi que el empresario no hacía nada; le pedí el manuscrito, me lo devolvieron, y, al llegar a casa, noté que las dos o tres páginas pegadas al principio y al final seguían pegadas; no las había abierto.

(Pío Baroja, Memorias) $^{1}$

Hablar de la producción teatral de Pío Baroja generalmente suscita una reacción de curiosidad, si no de indiferencia, porque su obra dramática es prácticamente desconocida². Muchos son

1 “Nuestra generación", Finales del siglo xix y principios del siglo xx, en Memorias, Minotauro, Madrid, 1955, p. 412.

${ }_{2}$ Entre los pocos estudiosos de literatura modernista que hacen referencia a ella están José Monl.eón, El teatro del 98 frente a la sociedad española, Cátedra, Madrid, 1975 y Gonzalo Torrente Ballester, Panorama de la literatura contemporánea, Guadarrama, Madrid, 1968. De las biografias suyas, las siguientes mencionan su actividad teatral: Sebastián Juna Arbó, Pio Baroja y su tiempo, Planeta, Barcelona, 1963; Miguel Pérez-Ferrero, Pío Baroja en su rincón, Ercilla, Santiago de Chile, 1940, y Vida de Pio Baroja. El hombre y el novelista, Destino, Barcelona, 1960. Algunos críticos se han referido a su teatro, pero muy 
los hispanistas que automáticamente asocian al escritor vasco con la novela del siglo Xx. Y hacen bien, puesto que es en ese campo donde Baroja se labró el sitial que ocupa en la galería de escritores españoles de nuestro siglo. El estudiante de la obra de Baroja, sin embargo, tiene el deber de reconocer que el autor, a pesar de su antipatía por el teatro (especialmente por el de su época), escribió varias piezas teatrales e incluso admitió públicamente en 1923, en un ensayo titulado "Con motivo de un estreno", que se le "había venido a la imaginación muchas veces la idea de escribir para el teatro...",3

Como algunos coetáneos suyos, entre ellos Unamuno, Antonio y Manuel Machado, Azorín y Valle-Inclán, Baroja sintió un rechazo total por el teatro realista-burgués de su época. Con el fin de remediar un escenario exento de vitalidad, espontaneidad e independencia frente a las convenciones literarias, las tentativas de Baroja demuestran una voluntad de renovación del teatro español de la segunda y tercera décadas del siglo XX. Esta intención fue caracterizada por dos cualidades fundamentales: el popularismo que adaptó a algunas de sus piezas dramáticas y la autonomía anárquica que se manisfestó en sus obras de mayor extensión. A causa de su falta de compromiso total con el teatro y sus propias dudas personales en cuanto a sus dotes de dramaturgo, Baroja nos legó un repertorio teatral sumamente irregular. Muchas de sus obras dramáticas no hacen más que subrayar las anomalías de este teatro. Sin embargo, algunas piezas suyas se prestan a una agrupación homogénea dado el obvio popularismo que las singulariza. Es nuestra intención demostrar que se pue-

de paso. Véanse, por ejemplo, Biruté Cirpljauskatté, Baroja, un estilo, Ínsula, Madrid, 1972, pp. 91-92; Luis Granjel, Retrato de Baroja, Barna, Barcelona, 1953, pp. 106, 122, 198, 204 y 282; Eloy L. Placer, Lo vasco en Pío Baroja, Vasca Ekin, Buenos Aires, 1968, pp. 67 y 205. Entre los artículos escritos específicamente sobre el teatro de Baroja están los siguientes: ANTONio Fernández Molina, "El teatro de Pío Baroja", SNo, 2 (1972), 68-72; Andrés Franco, "El teatro de Baroja", CuH, 299 (1975), 277-289; David Bary, "Un tango, una farsa y un esperpento", Íns, 1962, núm. 191, p. 7.

Gracias a la celebración del centenario de Baroja en 1973, una farsa suya, El horroroso crimen de Peñaranda del Campo, ha saltado a la vista del público bajo la iniciativa del Pequeño Teatro de Barcelona y "un teatro comercial madrileño". Por razones de la censura, la farsa nunca se puso en escena en Madrid, mientras que la representación hecha por el grupo barcelonés no mereció otro comentario que el de haber sido "digna de cualquier escena parroquial" (Franco, art. cit., p. 288).

3 "Con motivo de un estreno", Obras completas, Biblioteca Nueva, Madrid, 1951, t. 5, pp. 560-561. 
de hablar propiamente de una producción teatral barojiana y que, a pesar de todo, existe cierta unidad en ella.

\section{El problemático Conjunto de las obras teatrales de Baroja ${ }^{4}$}

Entre 1922 y 1937 Baroja escribió siete piezas dramáticas: La leyenda de Jaun de Alzate ${ }^{5}$, en 1922; un boceto dramático titulado ¡Adiós a la bohemia! en 1923; tres piezas breves escritas en 1926 para ser representadas en "El Mirlo Blanco"'6 (la "farsa villanesca" titulada El horroroso crimen de Peñaranda del Campo, el sainete llamado Chinchín comediante o las ninfas del Bidasoa, y Arlequin, mancebo de botica o los pretendientes de Colombina, de orientación farsasainete); y dos dramas de mayor extensión sin subtítulos genéricos que fueron escritos respectivamente en 1929 y 1937, El ' $n o c$ turno" del hermano Beltrán y Todo acaba bien... a veces?

${ }^{4}$ Como ha indicado Andrés Franco en su artículo de 1974, uno de los problemas que se presentan al estudiar el teatro de Baroja consiste en determinar cuáles de sus obras constituyen una auténtico empeño teatral y cuáles son novelas dialogadas que se prestan a una representación escénica. Para un acercamiento a este problema véase el anteriormente citado artículo de Franco, pp. 279-281.

No obstante los varios sistemas utilizados por críticos como, por ejemplo, Franco, en clasificar las obras de Baroja, creemos que es importante tener en cuenta lo siguiente: primero, que la disolución de fronteras tradicionales entre la novela, el ensayo y el teatro es parte de la innovación noventayochista según se puede ver en las obras de Unamuno, Azorín y el mismo Baroja; segundo, que Baroja tuvo parte en la clasificación de sus obras que habían de aparecer en Obras completas (publicadas en 1951 en Madrid por Biblioteca Nueva) y, siendo así, clasificó específicamente como "teatro" sólo las seis obras que vamos a enumerar a continuación en el texto de este artículo; tercero, que Baroja opinaba que el teatro únicamente tenía vigencia si era un teatro para ser leído, de modo que el valor de la palabra hallada y el teatro como espectáculo no eran factores importantes en su concepción del teatro. Véase lo que dice BAROJA sobre esto en "Crítica", El escritor según él y según los críticos, en Memorias, p. 1243.

5 La palabra “jaun" en vascuense significa "señor". Véase Placer, op. cit., para un estudio de la dimensión vasca en las obras de Baroja.

${ }^{6} \mathrm{El}$ teatro de cámara fundado por la cuñada de Baroja, doña Carmen Momé de Baroja. Entre 1926 y 1927 representó varias piezas experimentales tanto españolas como extranjeras. Para una lista de éstas consúltese ENRIQUE Díez-Canedo, Artículos de crítica teatral: el teatro español de 1914-1936, J. Mortiz, México, 1968, pp. 149-174.

7 Todas estas obras proceden de Obras completas, Biblioteca Nueva, Madrid, 1951. Arlequín y Chinchín están en el tomo 8, mientras que las otras están en el tomo 6 . A partir de aquí todas las referencias a estas obras serán inclui- 
No es ningún secreto que Baroja nunca se sintió a gusto con el género dramático, como lo atestiguan las frecuentes expresiones de desprecio por el teatro que dejó escapar de vez en cuando en sus ensayos ${ }^{8}$. Baroja mismo admitió repetidas veces que el género dramático nunca le había interesado mucho y que raras veces había asistido al teatro ${ }^{9}$. Sobre los dramaturgos franceses y europeos de su época, dijo, por ejemplo, que no iría a verlos aunque le regalasen el palco ${ }^{10}$ y que prefería pasear por los barrios bajos de Madrid, escuchando las canciones populares de Chueca, Barbieri, Chapí, y otros ${ }^{11}$, y observando aquellos aguadores, vendedores, ciegos, jóvenes, chulaponas, etc. ${ }^{12}$, que constituían lo que él designaba los "tipos"'13 que animaban la "comedia humana" de las calles madrileñas de principios del siglo.

A pesar de esta confesada antipatía, Baroja fue el crítico dramático de El Globo por casi un año (1902-1903), tomó parte como actor en las representaciones de "El Mirlo Blanco" y fue invitado por Carlos Arniches a colaborar con él en la composición de varios sainetes ${ }^{14}$. Añádase que el reducido número de sus obras de teatro tiene paralelo en las pocas representaciones que se hicieron de ellas. De las seis obras específicamente designadas "tea-

das entre paréntesis en el texto del artículo y estarán acompañadas de las siguientes siglas: Arlequin: A, Chinchin: CC, El horroroso: H, El "nocturno": N, La leyenda: L, y Todo acaba bien: T.

8 Véanse, en particular, los siguientes ensayos: "Nuestra generación", "Primeros libros", "Personas conocidas", "Escritores, bohemios y políticos" y "El escritor según él y según los críticos", en Memorias.

${ }^{9}$ Consúltense las siguientes páginas de BAROJA en Memorias: "Nuestra generación", pp. 298 y 300; "Primeros libros", p. 436; "Personas conocidas", p. 528. 841 .

10 "Los dramaturgos", Conversaciones en París el año 39, en Memorias, p.

11 "Nuestra generación", p. 301.

12 Sebastián Arbó, op. cit., p. 79.

${ }^{13}$ Es la expresión empleada continuamente por Baroja a lo largo de todos sus artículos de crítica dramática para El Globo. Véase "Crítica arbitraria", Divagaciones apasionadas, en Memorias, pp. 546-560.

${ }^{14}$ Hablando de lo que Arniches le propone en cuanto a la colaboración de los dos en la composición de unos saínetes, dice Baroja: "Al despedirme de Arniches y al ir a la Biblioteca Nacional pensé en el pro y el contra de una proposición así: yo era viejo ya para desviarme de un camino [...] ¿para qué iba a cambiar vida y a pretender ganar dinero? No valía la pena [...] No tenía afición al teatro, ni siquiera por el público ni por los cómicos, ni quería tener más dinero que el necesario para vivir. No creía que pudiera hacer nada que estuviera medianamente bien. Aun teniendo afición salen las cosas mal, no teniéndola tienen que salir peor" ("Escritores, bohemios...", p. 647). 
tro" por él, Arlequín fue representada en febrero y abril de $1926^{15}$ por el teatro de cámara de su cuñada; ;Adiós...! fue representada en 1923 en el Teatro Cervantes de Madrid, luego en 1926 por "El Mirlo Blanco"'; y El horroroso no fue estrenada hasta 1973 por un grupo teatral barcelonés dirigido por María Luisa Oliveda ${ }^{16}$. Que sepamos, sus otras obras teatrales no han sido representadas nunca.

Así pues, aunque el teatro barojiano sólo cuenta formalmente con las siete obras que hemos enumerado, su manejo de muchos aspectos del teatro popular demuestra un sorprendente conocimiento del teatro en general. Lo que sobresale, por último, de su reducida producción teatral es un espíritu anárquicamente libre para hacer con sus obras lo que él quería, sin preocuparse de ser aceptado o no, tanto por las compañías teatrales y los críticos como por el público. Examinemos, entonces, estos dos rasgos de su teatro.

\section{LO POPULAR}

DAvid BARY, en su ensayo titulado "Un tango, una farsa y un esperpento", opina que lo popular le sirvió a Baroja como vehículo para burlarse de "lo verdaderamente popular"' 17 , esto es, que la canción popular en los sainetes de Baroja demuestra el " $m a l$ gusto, [la] falsedad y [la] barbarie"'18. Pero la continua alusión de Baroja a esos "tipos" de los barrios bajos madrileños y la falta de interés de nuestro escritor por el teatro burgués de la época desacreditan la idea de Bary. Lejos de burlarse de lo popular (manifestado en forma de canciones, "tipos" o acontecimientos callejeros), Baroja veía en ello un medio de restaurar la vitalidad y el dinamismo al agotado, aburguesado y aburrido teatro realista de su época. Y si algo lo atraía al teatro no era la fingida representación de las grandes salas de Madrid, sino la verdadera emoción humana de otra clase de espectáculo: el de las calles, ese que se desenvolvía a diario alrededor de él (como, por ejemplo, la ejecución de la criada-asesina del crimen de Fuencarral) ${ }^{19}$.

Ante esa clase de entusiasmo por lo popular, es lógico que al hablar de sus gustos literarios exprese Baroja su preferencia por

${ }^{15}$ Franco, op. cit., 286.

16 Véase la nota final del artículo de Franco, p. 288.

17 BARY, op. cit., p. 7.

${ }^{18} \mathrm{Ibid}$. (lo que va entre paréntesis es mío).

19 Sebastián Arbó, op. cit., p.85. 
el género chico y la canción popular. En la escala de valores literarios de Baroja, uno de los peores vicios era la falsa retórica; por eso, indudablemente, se sintió tan atraído al sainete que, según él, vibraba de vida y calor humano ${ }^{20}$. En su opinión, Arniches era el mejor sainetero madrileño de la época ${ }^{21}$, y sólo en los sainetes andaluces de los hermanos Quintero y en las piezas de otros saineteros desconocidos, como Manuel Rodríguez ${ }^{22}$ y José María Mathéu ${ }^{23}$, era posible hablar de un auténtico género chico inspirado en el ejemplo de Arniches ${ }^{24}$. Sus reseñas críticas para El Globo siempre se concentraban en las mismas características que para él perjudicaban y debilitaban el teatro de aquellos años: la retórica altisonante, la frialdad y la falta de espontaneidad. No se olvide, por ejemplo, lo que dice de Benavente y Echegaray. De Alma triunfante de Benavente, estrenada el 3 de diciembre de 1902, opina que "la obra [...] parecía sepulcral [...] es un drama gris, triste, verdaderamente deprimente" ${ }^{25}$. Sobre La escalinata de un trono de Echegaray, estrenada el 20 de febrero de 1903, dice que "todo aquello es frío, muerto; no tiene alma, ni vigor, ni sangre"" 26 .

De estos y otros comentarios aislados se pueden deducir los siguientes criterios fundamentales para el teatro barojiano: primero, que los personajes sean "tipos" rebosantes de esa vida y ese vigor que les faltaban a las figuras de cartón del teatro de la alta comedia de costumbres burguesas; segundo, que la obra se sature de espontaneidad y calor humano. No le importaba a Baroja que "el hombre espontáneo fuera un bruto y un tosco", 27 , con tal que hablara un lenguaje natural, de acuerdo con su personalidad y oficio. Buscaba infundir en su teatro la misma sensación vital que latía en los viejos barrios bajos de Madrid. Si brotaban de la vida real, él prefería los detalles grotescos y anodinos al refinamiento burgués con sus diálogos pulidos y su tonalidad seria.

Así definido el "popularismo" de Pío Baroja, vemos en las tres piezas escritas en 1926 para "El Mirlo Blanco" la cristalización de la dimensión popular. Cada una de ellas está repleta de

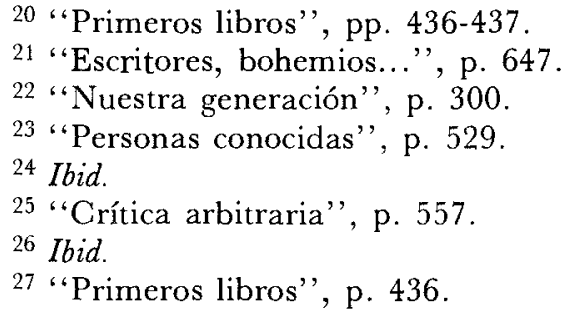


personajes que vienen de la tradición del teatro popular. Los protagonistas de Chinchín son miembros de una compañía teatral ambulante que llega a una pequeña aldea un domingo por la tarde para animar las fiestas pueblerinas. Esta dimensión popular se extiende al pueblo del Bidasoa, en el cual se oyen y se ven escenas típicas: el "Cantor callejero"' cuyas canciones recuerdan las de los ciegos, una breve discusión absurda e inconclusa entre el Maestro y el Secretario sobre la estadística y sobre si llueve o no, un diálogo entre García y Puchol que introduce el tema de las fiestas del pueblo, y otra breve conversación entre Bacalao Sin Tripas y Chorroch, que anuncia la llegada de la tropa de Chinchín, el dueño cuyo nombre sugiere un tipo de música popular y calleje:a. De una manera u otra, están presentes todos los "tipos" que caracterizan esas pequeñas aldeas españolas: el Maestro y el Secretario, Puchol el catalán, García y Chorroch, de la clase baja, que defienden los valores de su pueblo, y el rector cuya presencia es sugerida por la canción del "Cantor callejero" (CC, p. 668). A esta lista de "tipos" pueblerinos se añade otra: los "actores" de la compañía de Chinchín, entre los cuales se destacan Azucena, Chiquita, Hércules y las hermanas Esmeraldas.

Mientras que el "Cantor callejero" de Chinchin no desempeña otro papel que el de añadir al color local del pueblo, el Tuerto (de El horroroso) con su cartel de feria, cumple con su papel tradicional de cantar el asunto que ha de servir de nexo a la farsa: el caso del grotesco crimen de antropofagia del Canelo que, según la canción del Tuerto, mató, descuartizó y luego comió a su amante, la Sinforosa. Todo el primer cuadro de la farsa es un tejido de reacciones al crimen: mientras canta el Tuerto su versión personal de lo que ocurrió, se entrelazan las reacciones de varios personajes genéricos, como el tío Pamplinas, un Aldeano y algunos Mozos del pueblo. Todos los demás personajes de la farsa representan otro desfile de "tipos"; en primer lugar, los hay que forman parte del equipo de los administradores de la justicia en Peñaranda: el señor Severo, que es el magistrado de la Audiencia territorial, el Duque, el Director de la cárcel de Peñaranda y el tío Lezna, el verdugo. En segundo lugar, los representantes de los otros estamentos sociales: el padre Ratera, el doctor Cándido, que representa los nuevos acercamientos psiquiátricos a la patología criminal, la Marquesa que intercede a favor del preso para satisfacer las peticiones de su doncella, la Milagros y, por fin, el Canelo, que es el pobre chico falsamente acusado y que sirve de blanco para los abusos de la sociedad. Cada uno de estos personajes arquetípicos representa un punto de vista social referente 
a la culpabilidad del Canelo y, como tal, le sirve a Baroja para su propia crítica social.

De las piezas cortas, son los personajes de Arlequín los que se comparan más fácilmente con las figuras de cartón de la commedia dell'arte, otra clase de teatro popular: Arlequín, el enamorado de Colombina y aprendiz del boticario, Colombina, la mujer cuyas picardías atraen a todo tipo de pretendientes, y el señor Pantalón, el padre de la chica y dueño de la botica. Hay, además, otra clase de personajes "típicos" que integran y dan un tono popular a la obra: Brígida, la criada del viudo Pantalón, la Duquesa, que es la recién llegada madre desconocida de Arlequín y que descubre que el mancebo de botica es su heredero y no simplemente una persona de baja calidad como todos piensan, y los preten dientes de Colombina, que representan los pilares de la sociedaa del pueblo: el sargento, el veterinario, el maestro don Perfecto y el doctor Bártolo.

El asunto de estas piezas cumple fielmente con los propósitos del sainete y la farsa: hacer reír al público. En las tres, la comicidad emana de varios trucos lingüísticos que dan pie a las situaciones cómicas. Todo el argumento de El horroroso se concentra en el grotesco crimen de antropofagia que hemos mencionado. Se aumentan las dimensiones grotescas de la farsa en el segundo cuadro, a lo largo del cual el Canelo tranquilamente confiesa su “culpa', come con entusiasmo su última cena, y se prepara a morir bebiendo una copa de anís, fumando un cigarro y recordando las "nalgas" de una actriz que había visto "en el cine de la Encomienda" (H, p. 1271). Cuando el Canelo oye al Director de la cárcel preguntarle: "¿Qué era eso de que habías comido un pedazo de carne de la Sinforosa y que sabía a cerdo?"' (H, p. 1271), despierta de un sueño y le contesta: "Era la gallina de casa de mi madrastra, a la que llamábamos así" (H, p. 1271). Toda la seriedad del crimen se derrumba al oír su respuesta soñolienta, que no tarda en poner de relieve la estupidez de los dispensadores de la justicia, cuyo egoísmo es literalmente montado en escena mediante el retrato que les saca el "Fotógrafo [...] melenudo [...] de La voz de Peñaranda, de El despertar de cabezón y de El Globo terráqueo..." (H, p. 1272)28. Lo que colma a estos "grandes señores"

${ }^{28}$ Aquí la antipatía de Baroja por la prensa se vislumbra en el sarcasmo implícito en los títulos de los diarios que el "Fotógrafo" representa. (Para sentir el odio de Baroja hacia la prensa y el periodismo en general, consúltense los siguientes ensayos suyos que aparecen en El tablado de Arlequín F. Sempere y Compañía, Madrid, 1904: "Santa Austeridad”, pp. 14-15; "La novela", pp. 145-147; "Silverio Lanza", p. 153.) 
de la absurda comicidad que los pone totalmente en ridículo es la fantochería con que cada uno de ellos se acerca al fotógrafo y recita un romance apropiado a su oficio, para luego retirarse. El cuadro se cierra con los cuatro puestos en fila, cada uno con el signo de su oficio: "el tricornio [...], el birrete [...] y el libro" (H, p. 1273). A la vez que el fotógrafo les saca el retrato, recita el romance "del horrible crimen de un pueblo antropófago y brutal',.

Lo risible de Arlequín proviene de los retruécanos que resultan de las equivocaciones lingüístico-semánticas del mancebo de botica, tanto cuando trata de recitar en latín ciertas fórmulas de la profesión como cuando se equivoca en su u so de palabras, en forma intencional o no intencional. Cuando sabe lo que dice, Arlequín no distingue fonéticamente entre palabras. Por ejemplo, "veterinario" se convierte en "vete, urinario". En otros contextos, la confusión que sale del juego de palabras es más inocente $y$, por lo tanto, lleva el asunto a una mayor comicidad:

ARleQUín $Y$ ¿qué le pasa a la madre superiora?

PANTAlón Al parecer, está un poco apretadilla.

ARLEQUín $\mathrm{Y}$ ¿qué es lo que le aprieta a esa señora?

Pantalón Parece que no es el zapato.

ARLEQUín El zapato me figuro que no le apretará, porque lleva sandalias.

Pantalón Pues por eso no le puede apretar el zapato. Además, que es una tranquilidad para el espíritu saber dónde le aprieta a uno el zapato. Así que conténtate con saber que la madre superiora tiene el muelle un poco fuerte.

ARLEQUín ¿El fuelle?

(A, p. 673)

Es esta clase de equívoco la que forma la base de la serie de escenitas comiquísimas entre Arlequín y los otros pretendientes de Colombina. Los retruécanos se amontonan y facilitan la procesación a la botica de los señores que quieren pedirle la mano a la joven; con cada uno de ellos, Arlequín se vale del debido juego de palabras para despacharlos y quedarse solo con ella. A veces la doble significación de sus palabras lleva al humor negro, como es el caso en la escena entre Arlequín y el Sargento, en la cual Arlequín se venga de los avances amorosos de éste con Colombina mediante el arreglo del pantalón roto del sargento:

ARLEQUín (Vuelve con una aguja de a cuarta y un bramante grueso.) La señora Brígida ha ido a comprar aza- 
frán, y Colombina está arreglando el canario. Yo le coseré el pantalón.

PAntalón (Al Sargento.) Nada, nada; eso se arregla en seguida. (Pantalón sube a su casa.)

ARlequín (Se acerca al Sargento.) A ver. (Le da una puntada.)

El SARGEnTo ¡Ay, ay! ..., que me pincha en el...

ARLEQUín Pero si eso no es nada, hombre. Pues, no es usted poco gallina. Es que me he equivocado. Como tiene usted la piel tan oscura, creía que era la tela.

(A, p. 677)

En otros casos, la comicidad es menos atrevida: "paralísparálisis", "apéndice-apendicitis", "diapasón-diaquilón", etc. Añádase que la menos risible de las tres obritas es Chinchin donde, de acuerdo con esto, la ingenuidad de la joven Azucena les da a tales palabras como "trasero", "cornudo", "cuerno" y "Papá Michel" una doble significación que provoca las debidas reacciones cómicas. Es en esta pieza donde Baroja superó la simple comicidad del sainete para hacer resaltar sus dimensiones absurdas, gracias a las cuales le resultó más fácil ridiculizar una sociedad estamental que le parecía absurda en sí.

Con todo, las dimensiones cómicas de las obras de 1926 siempre sugieren un humor teñido de negro y de temas licenciosos: las ninfas del Bidasoa, los pieles de la guantera cuya tienda está al lado de la botica del señor Pantalón, el pinchazo que Arlequín le da al sargento; la antropofagia del Canelo; el lenguaje universal de "ipellizcar el trasero!..." (CC, p. 692) que les sirve a Azucena y a sus amigas de mejor vehículo de comunicación que el esperanto, etc. Son temas y palabras cuyo doble sentido nunca habría aparecido en una obra realista de alta burguesía por miedo de ofender las sensibilidades burguesas del público. Tal parece que Baroja, continuando, aunque muy tarde, la tendencia de "épater le bourgeois"'29 iniciada por Alfred Jarry en Ubu roi (1896), había pensado específicamente en esa anticipada reacción burguesa. Por eso llenó su teatro de tantos elementos licenciosos que, además de producir un choque en su público, le brindaron una alternativa al teatro burgués de la época. No debemos olvidar tampoco que estas tres obras fueron escritas específicamente para el teatro de cámara de su cuñada y, por lo tanto, iban dirigidas a un reducido grupo de entusiastas que habrían aplaudido sus 178.

${ }^{29}$ Gonzalo Sobejano, Forma literaria y sensibilidad social, Madrid, 1970, p. 
tentativas de restaurar la energía a la anémica escena española de aquellos años.

\section{LA AUTONOMÍA ANÁRQUICA}

Entre los críticos que se han fijado en la característica barojiana por excelencia, la del individualismo, está Biruté Ciplijauskaité, para quien ese "fondo anárquico" 30 es la fuente de toda la actividad literaria de Baroja. Estejuicio, que normalmente se aplica a la novelística barojiana, tiene cada vez más valor cuando se estudian sus obras de teatro. En ellas se percibe fácil e inequívocamente la independencia con que Baroja se aproximó al género dramático. Siendo así, dicha independencia se manifiesta principalmente en la estructura de las obras, las intromisiones del "Autor", el uso de la acotación, y la extensión desmedida de tres obras suyas que veremos a continuación.

Primero, la estructura de sus piezas dramáticas. Como veremos más adelante, La leyenda está dividida en cinco "partes" larguísimas. La estructura del sainete y de las dos farsas tiende hacia la división tradicional en dos o tres "cuadros", con excepción de Arlequín, que sólo tiene uno. En El horroroso se percibe la intención de Baroja de romper con los moldes convencionales al agregar un prólogo, titulado "El Autor", y un epílogo a los tres cuadros. Es una improvisación que recuerda la irregularidad estructural de La leyenda, como veremos en seguida. El "nocturno", por lo demás, es aún más extravagante en sus veintiuna partes, mientras que Todo acaba bien vuelve a las tres "partes" tradicionales.

Fijémonos más detenidamente en la estructura de La leyenda y El "nocturno"'. La leyenda, porque es la primera obra que Baroja escribió para el teatro y, por ser la primera, nos da una indicación de su actitud tocante al resto de sus obras. Ello es así en $E l$ "nocturno" porque, con El horroroso, sostiene la línea anticonvencional inaugurada por La leyenda. Cada una de las cinco partes de La leyenda tiene un "Intermedio" final en que se repite con ligeras variaciones un estribillo que explica la razón por la cual el supremo dios vasco, llamado Urtzi Thor, huye de sus dominios vascos:

EL CORO - La aurora comienza a sonreír en el cielo. La aldea está desierta. ¿Quién es ese hombre feroz de ojos torvos y de barba roja que pasa subido en un carro tira-

30 Ciplijauskaité, op. cit., p. 58. 
do por machos cabríos? ¿Por qué lleva un caldero en la cabeza? ¿Es un hombre o es un dios? Es Thor, Urtzi, hijo de la Tierra, el más fuerte de los dioses. Urtzi Thor se detiene y contempla el caserío de Alzate y habla melancólicamente. ¡Oigamos, oigamos lo que dice!

Urtzi Thor - ¡Adiós! ¡Adiós! ¡Pirineos próximos al océano! ¡Montes suaves y luminosos! ¡Valles verdes y templados! ¡Aldeas sonrientes y sonoras! ¡Adiós, viejos vascos altivos y joviales de perfil aguileño! Me vuelvo a mis desiertos helados. ¡Adiós! ¡Adiós!

Con excepción de la segunda parte, que empieza con lo que se llama "Prólogo de los Diablos", las otras cuatro partes comienzan con una intromisión del autor, que formalmente se titula " $\mathrm{Ha}$ bla el Autor', y unạ'acotación. La obra tiene también un "Epílogo" en que hay algo que se parece a una acotación narrativa donde vuelve a hablar el autor, así como una discusión dialogada entre varios personajes nuevos sobre la posible salvación de Jaun de Alzate. Pero el "Epílogo" no cierra la obra. La obra termina con el "Adiós final" de los mismos dos dialogantes de los "Intermedios", Urtzi Thor y el Coro, confiriéndole así una circularidad perfecta desde el doble punto de vista de la estructura y la temática. Además del marco que constituyen los "Intermedios" y la parte llamada "Habla el Autor", cada una de las demás partes tiene un título y está subdividida en secciones -15 , $11,23,21$ y 11 respectivamente - que hacen las veces de escenas, marcan la entrada y salida de lós personajes, e indican los cambios de escenarios. En total, 81 "escenas" que corresponden a una de las intenciones - la épica - del autor, como veremos más adelante. Por otra parte, El "nocturno" es menos complicado estructuralmente, pero demuestra la misma osadía estructural que la "leyenda" escénica de 1922. Está dividido en veintiun partes, cada una con su propio título y una larga acotación en prosa que, además de precisar tradicionalmente la ambientación, el vestuario y el habla de los personajes, describe el escenario. El cambio de escenas no se consigue mediante una división formal, sino a través de las interrupciones proporcionadas por el uso de otras acotaciones más cortas. Aquí la audacia de Baroja se hace patente mediante la explotación al máximo de la acotación teatral, como veremos más adelante. 
La segunda manifestación de la independencia con que Baroja escribió su teatro se basa en las palabras de un fingido "Autor" que se dirige al público. La leyenda y El horroroso son las únicas obras de Baroja en las cuales el autor habla directamente con su público al principio y durante las obras. Aunque no se identifica abiertamente con Pío Baroja en La leyenda, el "Autor" no finge ser otro; simplemente dice que, siendo el autor de la obra, es "un poeta aldeano, poeta humilde [...] del país del Bidasoa" (L, p. 1101). En El horroroso, el autor se llama "Petito Rubores" y, junto con sus "compañeros de la Prensa de Peñaranda" (H, p. 1257), forma parte del público que se ha reunido para ver la representación de su obra.

En las dos obras el "Autor" le prepara al público tanto el argumento como los aspectos técnicos de la obra que está a punto de ver. Declara que él es el autor y, que por esa razón, ha gozado de plena libertad y derecho para hacer con su obra lo que ha querido. El "Autor" de La leyenda se entromete tres veces, enfatizando cada vez más su propia autonomía como creador de la obra. Cuando se dirige al público al principio de la representación, se parece a un bardo medieval que, con la antigua excusa de la humildad, repite constantemente lo toscos que son sus procedimientos literarios: "Como hombre de campo, no poseo conocimiento del arte teatral, no sé mover los muñecos en el retablo, y no espero congregar a un verdadero público..." (L, p. 1101). Dice que quiere "cantar esta tierra y este río..." vascos poniendo en escena "ante vuestros ojos unas escenas vascas", valiéndose de toda clase de procedimientos que le vengan "a la imaginación". En vez de decir que su obra es un drama, la llama "leyenda", admitiendo que "verdaderamente no sé lo que es, no he pensado en ningún modelo al escribirla". Explica la genealogía de su protagonista Jaun de Alzate, diciendo que su explicación se basa más en lo legendario que lo histórico, hecho que da más relieve a las dimensiones populares de la obra. De acuerdo con los principios de la leyenda en general, advierte al espectador de los "anacronismos" que tiene la obra, pero dice que no importan porque "¿Quién sabrá si acierto o si yerro?" (L, p. 1102). Su actitud socarrona no puede ser más evidente, pues los otros parlamentos del "Autor" que siguen no hacen más que poner de relieve su autoridad para hacer lo que quiere con su obra. Al darse supuestamente cuenta, en la cuarta intromisión, de la reacción del público a su obra, no se disculpa, como es de esperar de tanta "humildad" inicial, sino que repite cinco veces una admonición parecida a la que hizo Unamuno tocante a su teatro: si no les place la obra teatral que están 
viendo, que se vayan al cine $\mathrm{e}^{31}$. En la quinta y última intromisión, su independencia se ha afirmado: "Veo que fruncís el ceño... Yo concluiré para dos amigos y para mí" (L, p. 1141); y suelta otra disculpa: que había pensado llevar a su protagonista a tales extremos, pero "él se ha precipitado en esta dirección sin que" (L, p. 1162) él, el Autor, lo haya podido "retener". Deja al espectador ante los principios de una doble autonomía literaria: la del autor mismo frente a su obra y, en otro plano, la de los personajes ficticios frente a su autor. Dos veces autónoma, entones, La leyenda de Jaun de Alzate.

Cuando Pepito Rubores aparece ante el público en El horroroso para defender su obra, tanto el tono como el propósito de su apología son sarcásticos y ficticios. Empieza diciendo que, según la "costumbre establecida en el teatro griego y romano" ( $\mathrm{H}, \mathrm{p}$. 1257), el autor, "en su nombre o en el de uno de sus personajes", explicaba el argumento de la obra; Pepito, no tan motivado por esa antigua costumbre literaria como por sus "compañeros de la Prensa”, que quieren que se sepa sin lugar a dudas quién es el autor, declara abiertamente que él escribió la obra. Esta clase de declaración aviva la curiosidad del lector-espectador, pues si es tan fuerte el deseo de los "compañeros" de Pepito, aun si es una ficción, de que se ponga en claro que no son ellos los responsables de la obra, es seguro que encierra algo inadmisible. Si no hubiera una crítica negativa implícita, Pepito no habría tenido que defenderse de esta manera:

Algunos dirán [...] que no se deben llevar las escenas de un tablado a otro tablado y que no se deban ejecutar en el escenario de los teatros más que piezas musicales alegres. Personad que la fraseología legal se mezcle a la teatral; pero ¿qué mejor higiene que convertir lo lúgubre en grotesco y poner un poco de ridículo en el otro tablado y en sus alrededores? -Quizás algunos estetas refinados nos reprochen cierta intención social. ¡Qué se va a hacer! No hemos llegado en Peñaranda a la deshumanización del arte... ${ }^{32}$

(H, p. 1257)

Aunque el lector-espectador todavía no está seguro de la significación del juego de palabras entre "tablado" y "ejecutar",

31 Recordemos las palabras de Unamuno en cuanto al drama "desnudo" por el cual abogaba tanto: "Hay que acostumbrar a la gente a que vaya al teatro a ver, sí, pero más que a ver a oír [...] y los que no quieren oír y sólo ver, que se vayan a un cine" ("Prólogo", Teatro completo, ed. Manuel García Blanco, Aguilar, Madrid, 1959, p. 87).

${ }^{32}$ Los subrayados son míos. 
las palabras de Pepito le dan una sensación de cierta picardía paródica en cuanto a la obra. Sólo después de leer-ver la obra se da uno cuenta de que la declaración del autor se refiere tanto al argumento como a la crítica de la farsa en general. Pepito hace más que declararse autor de la obra; se identifica como un hombre de letras que conoce las costumbres del teatro grecolatino y que está al tanto de la "deshumanización del arte" de la que habló Ortega y Gasset en $1925^{33}$. No olvidemos tampoco que, al decir " mis compañeros de la Prensa de Peñaranda", sugiere que es periodista. Al enfrentarse tan descaradamente con su público, Pepito crea un público ficticio que va incorporado a la farsa, promete tratar un tema algo licencioso, da su propia respuesta a las tendencias estéticas de la época, y se separa definitivamente del resto de los escritores del momento. Cuando termina su "diálogo" con el público, el espíritu guasón de su predecesor, esto es, el "Autor" de La leyenda, se ha convertido en una burla total. Su "invocación" final:

Y ahora, señores, un poco de benevolencia. Abrid los ojos, abrid los oídos, carraspead, sonaos bien... y si tenéis una patata dura en el bolsillo... sustituidla por ... uno de estos ricos y sustanciosos tomates que producen nuestras celebradas huertas... ¡Salud!

$$
\text { (H, p. 1258) }
$$

El horroroso y La leyenda son dos obras teatrales de distinta clasificación: la primera es una farsa, la segunda, según Baroja, una leyenda vasca puesta en escena. No obstante la orientación genérica de las dos obras, las declaraciones de sus "Autores" establecen entre ellas una relación basada en la intención autónoma y el tono sarcástico del autor: las dos ponen de relieve la filosofía teatral con que Baroja concibe sus obras dramáticas en general, y sirven de manifiestos sobre el arte de hacer teatro, arte que gira alrededor de la independencia creativa de tema y estructura, la sencillez de lenguaje y expresión, y la vuelta a un teatro de inspiración popular. A causa de la falta de representaciones de estas piezas, es imposible saber si el papel del "Autor" que habla con

${ }^{33} \mathrm{Su}$ referencia a Ortega y Gasset se parece a lo que dijo Baroja en $E l$ escritor según el ...: "Yo siempre he mirado con una gran indiferencia todas esas invenciones ridículas con nombres rimbombantes que durante el siglo $\mathrm{XX}$ nos han querido dar por manifestaciones de genialidad" (p. 1211). Los "nombres rimbombantes" a que él se refería eran el superrealismo, el existencialismo y el psicoanálisis. 
el público lo hubiera hecho el propio Baroja u otra persona, o, por otra parte, si las introducciones se hubiesen limitado al texto escrito en vez de ponerse en escena. Lo cierto es que la mera presencia del "Autor" ante el público para explicarle lo que va a ver se remonta a épocas medievales, cuando los faranduleros-bululúes ambulantes que iban de pueblo en pueblo se ponían de pie ante el público y hacían explicaciones parecidas. Como ya queda claro, el teatro de Baroja tiende a inspirarse en el teatro popular mucho más que el teatro realista; es una tendencia que fomenta una inconfundible voluntad de independencia que, a pesar de no ser programada por Baroja como tal, equivale a una auténtica tentativa renovadora tocante al teatro español moderno. Cuando el protagonista de El "nocturno", Beltrán, discute con su madre, la Duquesa, sobre los compositores musicales que él prefiere, resume perfectamente la concepción barojiana del teatro, de acuerdo con la preferencia de Baroja por la canción popular y el "tipo", callejero de los barrios bajos de Madrid:

Sí, es música de teatro, para gentes de mundo. No tiene esa verdad honda de lo popular. Esa romanza de la flor, por ejemplo, no es la canción que puede cantar un vasco un poco salvaje a una gitana de la que está enamorado. Es la canción de un señorito para ser cantada en un salón de París. Es el cromo bonito; para mí poca cosa. . .

(N, p. 1209)

Beltrán, rechazando las composiciones de Puccini, Wagner, Stravinsky y Strauss a favor de los nocturnos gesticuladores ${ }^{34}$ de Chopin, Beethoven, Mozart y otros, se rebela, a su manera, contra los mismos "cromos" criticados por Unamuno ${ }^{35}$ en muchos de sus ensayos de teoría dramática, pues los dos anhelan el retorno de las artes a su punto de partida creativo: el pueblo.

La tercera manifestación del individualismo de Baroja frente al teatro tiene que ver con la acotación, tanto desde el punto de vista estructural como desde la naturaleza del contenido y lo que se desprende de éste. En La leyenda y El "nocturno" las acotaciones hacen más que definir la escena y los decorados; sirven también de nexos anecdóticos que marcan el desarrollo temporal de cada hora, además de describir detalladamente la manera de vestir y

\footnotetext{
${ }^{34}$ Beltrán alude específicamente al "nocturno, un poco gesticulador y empalagoso de Chopín' (N, p. 1208).

${ }^{35}$ Consúltese a Unamuno, "Teatro de teatro", op. cit., p. 1158.
} 
hablar de los personajes, con gran riqueza de colores y elementos sensoriales. Por ejemplo, en El "nocturno":

Es de noche. Hay un olor penetrante, mixto del perfume de las flores de azahar y de claveles. El aire está tibio y el firmamento lleno de estrellas. Se oye el rumor de una fuente. La duquesa ha escrito a Beltrán para que vaya a verla.

(N, p. 1187)

Se incluyen tantos elementos de fondo que sería interesante ver si un director pudiera hacer de su puesta en escena una realización innovadora. Que sepamos, nadie lo ha intentado todavía. Nos tenemos que preguntar, entonces, si sería posible montar una acotación del tipo de la que da comienzo a El "nocturno":

El convento del Salvador está asentado en la costa atlántica andaluza al borde de la playa. Tiene el aire de una cúpula de azulejos, sobre la cual se levanta un nido de cigüeñas. Cerca se ve un arrecife negruzco con un faro de hierro. Al lado, un huertecillo de palmeras. Más lejos, una costa baja y verde con pinos. Enfrente, en el horizonte, sobre todo en el crepúsculo, se divisa Africa; en primer término, un acantilado blanquecino y, más lejos, montes de color rosáceo.

$$
(\mathrm{N}, \text { p. } 1177)^{36}
$$

Varias son las explicaciones que se pueden dar en cuanto a lo insólito de las acotaciones barojianas. Por una parte, responden a la voluntad del autor de infundir vitalidad a sus obras de teatro, mediante la incorporación de escogidos elementos de color local, dialectos regionales, la manera de vestir, etc. Se debe recordar también que Baroja, en su ensayo "Con motivo de un estreno' de 1923, dijo dos cosas: primero, que para él, "la única originalidad posible está en los detalles..."; pero segundo, que "en el teatro no puede haber detalles"'. La aparente contradicción resulta en un doble conflicto: desde el punto de vista teórico, Baroja opina que sólo la incorporación del detalle le puede conferir novedad, esto es, dinamismo, a la obra de teatro, pese a que no es practicable su realización. Desde el punto de vista de su manera de escribir, su atrevimiento le motivó a hacerlo como él creía oportuno, pese a cualquier contradicción o cualquier convención literaria:

${ }^{36}$ Los subrayados son míos. 
...he escrito, primero, para entretenerme, y después, para ganar algo... He dejado mis libros en la calle, y he pensado: allá ellos. Si valen, con el tiempo sobrevivirán y si no valen, se olvidarán...37

La certeza con que Baroja confiesa que escribe sus libros "sin plan" 38 también explica en parte el uso de tantas técnicas narrativas, propias del novelista, en sus acotaciones teatrales. En cuatro de sus piezas teatrales - La leyenda, El horroroso, El "nocturno" y Todo acaba bien - sus dotes de observador ${ }^{39}$ saltan a la vista, recordándole al lector-espectador que Baroja insistía en el teatro para ser leído, y que él mismo había empezado su carrera literaria confundiendo genéricamente sus primeras novelas con el teatro. Tres de las obras que él clasificó como "teatro" - Le leyenda, El "nocturno" y Todo acaba bien - nunca salieron del todo de esa confusión inicial y, como resultado, dependen excesivamente de la acotación, lo cual les cuesta la espontaneidad que Baroja tanto anheló y les confiere una pesadez y una tonalidad narrativa que, a la vez que aburren, tienden a imposibilitar su representación teatral. Por otra parte, es factible ver algunos aspectos de las acotaciones barojianas, y por extensión la estructura en general de sus piezas dramáticas, como manifestaciones de cierta óptica innovadora y juguetona propia del vanguardismo que florecía en Europa $^{40}$. Fijémonos, por ejemplo, en la "barca vikinga pintada de negro" (L, p. 1162) que viene a recoger a Urtzi Thor, el piano que "parece sollozar" ( $\mathrm{N}$, p. 1186), y las acotaciones como la que fija la primera escena de $E l$ "nocturno", que posiblemente tengan cierto valor cinematográfico. De todos modos, es seguro que el uso barojiano de la acotación teatral y la estructura tan irregular de algunas de sus piezas dramáticas corresponden a su espíritu independiente frente a la literatura en general, y al teatro en particular.

El cuarto aspecto de la autodeterminación de Baroja se ejemplifica en la extensión de La leyenda, El "nocturno" y Todo acaba bien. Estas tres obras más largas son también las más difíciles de categorizar y, por lo tanto, subrayan una vez más la autonomía anárquica de Baroja frente a su teatro. Cada una es, en realidad,

${ }^{37}$ Citado por Granjel, op. cit., p. 120.

${ }^{38} \mathrm{Ibid}$.

${ }^{39} \mathrm{Al}$ respecto, véase Pérez Ferrero, op. cit., pp. 108-117; CiplujauskaiTÉ, op. cit., pp. 36-37; Granjel, op. cit., pp. 94-106, ARBó, op. cit., pp. 84-163.

${ }^{40}$ Nos referimos, en particular, a tales "ismos" como el futurismo, el cubismo, el surrealismo, el creacionismo, etc., que iban fomentando una nueva sensibilidad estético-literaria. 
tan distinta de las otras que sólo se pueden clasificar las tres juntas bajo el denominador común de las anomalías implícitas en ellas. La estructura de La leyenda es sumamente irregular, como ya hemos visto. La acción dramática recorre los últimos años de la vida del protagonista y simboliza la desaparición del pueblo vasco con la llegada del cristianismo. El alcance de la acción es tan global que, además de hacerla la obra teatral más larga de Baroja, le da cierto espíritu épico: "Los Jaun Alzate eran de los más antiguos parientes mayores del país vasco..." (L, p. 1102). Esta "leyenda vasca" es como un saco lleno de recursos y temas que provienen de toda clase de obras literarias: hay escenas que son parodias de pleitos legales y de las letanías cristianas, muy parecidas a las parodias de Juan Ruiz en el Libro de buen amor ${ }^{41}$. Otras (en la cuarta parte) recuerdan el vuelo fantástico en el poema $E l$ laberinto de Fortuna, de Juan de Mena ${ }^{42}$ y el episodio de los espejos mágicos ${ }^{43}$ que ven Critilo y Andrenio en El Criticón de Gracián. Cuando el Bidasoa y el Monte Larrún, entre otros elementos del paisaje y la leyenda vascos, se presentan en escena y hablan ${ }^{44}$, se piensa en la Numancia de Cervantes (aún más, cuando habla Chimista, el perro de Jaun de Alzate ${ }^{45}$, se recuerda el Coloquio de los perros de Cervantes). Además de las reminiscencias literarias que constituyen escenas de verdadera fantasía, el diálogo de la obra cuenta con muchas irregularidades que interrumpen su continuidad (por ejemplo, el tercer apartado de la segunda parte que, con el subtítulo de "Nochebuena", consiste en unas breves acotaciones narrativas seguidas de una serie de exclamaciones como " $\mathrm{NNo}$ chebuena!' y “'Alegría! ¡Alegría”' (L, p. 1122). No hay ninguna indicación de la procedencia de las exclamaciones ni están escritas las acotaciones en letra bastardilla como se suele hacer, de ma-

${ }^{41}$ Fíjese, por ejemplo, en lo siguiente: La madre brUja - Lucifer./El co. RO - MISERERE NOBIS./La madRE BRUja. - Belzebuth, en mosquero./El coro - Miserere nObis./La MAdre bruja - Astaroth, de la Orden de los Serafines./El CORO - ORA PRO NOBIS./LA MADRE BRUJA — Sebaoth, el de la cabeza de asno./EL CORO —ORA PRO NOBIS (L, p. 1151)

${ }^{42}$ Jaun de Alzate y sus compañeros creen haber visto Babilonia, Etiopía, la China, etcétera (L, pp. 1157-1158).

${ }^{43}$ El diablo Chiquí habla de "unos espejos de los que deforman la figura" y a través de los cuales Jaun y sus amigos ven a Julio César, Nerón, Carlomagno, Mahoma, etcétera ( $\mathrm{L}, \mathrm{pp}, 1153-1154$ ).

${ }^{44}$ Nos referimos al parlamento del Bidasoa en la tercera parte y al del Monte Larrún en la cuarta parte (L, pp. 1131-1132 y 1159-1161), respectivamente.

${ }^{45} \mathrm{El}$ perro dice: "Mírame a mí, humilde, tranquilo, suspirando al lado del fuego. ¡Ésa es la vida!” (L, pp. 1170). 
nera que es imposible que el lector sepa cómo se escenificaría). En otras partes, el diálogo normal es interrumpido de repente por las disquisiones del Monte Larrún, la Paloma, el Ruiseñor, el Macho Cabrío, etc. Con todo, es fácil considerar La leyenda como la obra más estrambótica de todo el repertorio dramático de Baroja, además de apreciar en ella tal vez el mejor ejemplo, por la cuasiintertextualidad tan variada que acabamos de señalar, del cruce genérico entre novela y teatro que le causa tantos problemas al clasificador de estas tentativas teatrales.

En comparación con La leyenda, El "nocturno" es una obra estructuralmente sencilla y decididamente menos teatral. El trasfondo es musical, no sólo a causa del "nocturno"' compuesto por el protagonista Beltrán que sirve temáticamente de hilo conductor, sino también por el uso de las distintas composiciones musicales que se entrometen técnicamente en la acción: la canción popular del señor Pepe en la primera escena, el cante jondo andaluz y las saetas de la Semana Santa, las teorías del profesor de música que viene a hablar con la madre de Beltrán, y la canción vasca de la penúltima escena. Si no fuera por la música intercalada y audible, la obra no sería más que otra historia de un protagonista aventurero que, mediante la anagnórisis, llega a conocer a su verdadera madre y las circunstancias que la motivaron a abandonarlo cuando era pequeño. La obra en sí carece de espontaneidad y tensión dramática, posiblemente una de las razones por las que nunca fue estrenada.

La última pieza dramática barojiana es Todo acaba bien. Sorprendentemente, esta obra es la que más se parece al teatro realista que tanto odiaba Baroja ${ }^{46}$. Si La leyenda y El "nocturno" carecen de vigor dramático, al menos ofrecen escenas y recursos tan fuera de lo normal para el teatro de la época que podrían ser considerados experimentales, innovadores, y hasta anti-realistas. Todo acaba bien, sin embargo, no tiene nada de la rebelión barojiana que, por ejemplo, los "Autores"' fingidos de El horroroso y La leyenda ofrecen a su público. Se caracteriza, por el contrario, por un tremendo melodramatismo. La acción gira alrededor de los problemas de unos exiliados españoles que viven en el sur de Francia durante la Guerra Civil. Es la única obra de teatro de Baroja que posee una introducción puramente anecdótica, en la que se relata el pasado de la protagonista Carmen Godoy. Las escenas

46 Para una buena idea del desaliento que este teatro le produjo, véanse sus reseñas críticas escritas entre 1902 y 1903 para El Globo: "Crítica arbitraria', op. cit., pp. 546-560. 
entre ésta y su recién descubierto novio, Paco, van siendo cada vez más melodramáticas. La obra termina en una escena tan poco barojiana que el lector-espectador tiene que repetirse que está de veras ante una obra de Baroja:

Carmen (Lánguidamente y vibrando de pasión.) - ¡Adiós, Paco, adiós!

PACO - ¡Adiós, querida Carmen! (Se abrazan y se besan.) ¡Adiós, querida Carmen!

(T, p. 1253)

Si el lector-espectador ha leído cronológicamente el teatro de Baroja, esperaría que de esta escena se hiciera una parodia; no hay, sin embargo, elemento alguno que sugiera ni una ligera parodia del melodramatismo. Una de las pocas conclusiones que nos quedan frente a esta obra tiene que ver con circunstancias que Baroja mismo vivía durante aquellos años en que fue escrita: su exilio en París de 1936-194147. De la experiencia personal de Baroja en París, uno de sus biógrafos, Sebastián Juan Arbó, nos transmite unas palabras claves del autor mismo:

...El ser español [...] no era ninguna recomendación. España atrevesaba un mal momento; era una época de desprestigio total ante el extranjero: de desprestigio [...] de su vida, de su política, de sus costumbres... ${ }^{48}$

Aunque hay muy poco escrito para comprobar que el tratamiento que Baroja recibió durante su exilio en París fomentó el tema y la tonalidad de Todo acaba, es posible que estas experiencias suyas influyesen en la sentimentalidad anecdótica de la pieza. Nos limitamos a sugerirlo y dejar la obra como ejemplo de lo anómalo de la carrera teatral del autor vasco.

\section{GuATRo aspectos DEL MUNDO DRAMÁtico baROJIANO}

A pesar de las diferencias radicales que separan las obras teatrales de Baroja, hay cuatro aspectos que les dan la necesaria cohesión para permitirnos hablar del mundo dramático barojiano como un conjunto. En primer lugar, todas ellas, sin excepción, tienen como elemento de fondo un tipo u otro de música. A veces

47 GRANJEL, $o p$. cit., p. 157.

48 Op. cit., p. 221. 
la musicalidad, como en Todo acaba, es simplemente un recurso que le da color local al argumento; en otros casos, funciona tanto en el plano temático como en el técnico, como en El "nocturno" y El horroroso. La segunda característica es el pintoresquismo que acompaña la acción de varias piezas. La leyenda es un auténtico compendio de costumbres, creencias, ritos y canciones vascas ${ }^{49}$, contrapuestos a las creencias cristianas que poco a poco causan la desaparición de la cultura autóctona que representa Jaun de Alzate. En El "nocturno', la contraposición de costumbres regionales está repartida entre las prácticas andaluzas de la Semana Santa y la vida en un caserío vasco. Mientras que el título de Chinchín denota el vasquismo del pueblo que está cerca del río Bidasoa, dos breves conversaciones al principio del primer cuadro se desarrollan alrededor de temas regionales: en la primera, entre García y Puchol, se discute si el acento de éste es más catalán que "andalús" (CC, p. 689); en la siguiente conversación, entre Bacalao Sin Tripas y Chorroch, el énfasis está en la rivalidad entre los vascos y los franceses. Con Todo acaba, el escenario pasa a la ciudad fronteriza de Biarritz, donde se plantea la situación de los españoles expatriados durante la Guerra Civil de 1936.

Sea la escena vasca, andaluza o francesa, uno de los principales recursos empleados por Baroja al transmitirle al lectorespectador el sabor local de cada región consiste en el empleo de la canción típica en letra original. En La leyenda se cantan canciones en vascuence; en $E l$ " "nocturno"' se oyen el repique de la guitarra flamenca, la "música militar" (N, p. 1203), y las saetas que acompañan los pasos de las procesiones de Semana Santa; en Todo acaba se escuchan canciones de la época, como "Tout va très bien, madame la marquise" y otros "cuplés" parisienses.

El tercer aspecto del mundo dramático barojiano tiene que ver con el "blanco" contra el cual se dispara la crítica del autor. La leyenda censura frenéticamente el cristianismo. Los absurdos diálogos de Chinchín recaen tanto sobre la administración civil del pueblo como sobre la desabrida representación reatral de la compañía del protagonista. Ante el cartel de feria del Tuerto en El horroroso, unos estudiantes, aunque se burlan del arte "cubista o expresionista [...] o mamarrachista" (H, p. 1258), admiten que "tiene su gracia [...] como todo lo que es absurdo", como hemos visto, la crítica es feroz cuando va dirigida contra la injusticia y una sociedad que obliga a un hombre como el tío Lezna a hacerse ver-

${ }^{49}$ Cada canción escrita en vascuence está seguida de una traducción al castellano. 
dugo para poder mantener a su familia. Los ridículos pretendientes de Colombina en Arlequín representan la estupidez y la hipocresía de las instituciones estamentales. El "nocturno", por su parte, expone la superficialidad de la aristocracia y los seudo-intelectuales, que le causa a Beltrán una abulia mortal. Incluso Todo acaba tiene su "blanco": los prejuicios contra los españoles exiliados en Francia y el egoísmo humano, representado por el padre de Carmen.

El cuarto aspecto lo comparten todas las obras dramáticas escritas en los años veinte: la circularidad estructural. La acción de La leyenda empieza con el "Intermedio" dialogado del Coro y Urtzi Thor; a la pregunta retórica del Coro de quién es "ese hombre feroz de ojos torvos y de barba roja que pasa subido en un carro tirado por machos cabríos?"' (L, p. 1104), el dios vasco contesta diciendo "¡Adiós!' a la tierra vasca. Cuando termina la obra, el "Adiós final" del Coro y Urtzi Thor marca el alejamiento definitivo de éste y el reconocimiento completo de su dios de parte del Coro. Chinchín comienza con la llegada de la compañía de farsantes de Chinchín al pueblo y las palabras del dueño-bululú para atraer a la gente. El sainete termina con la disolución de la compañía, pero con las mismas palabras de Chinchín: "Racataplán, racataplán, racataplán. Yo soy Chinchín Comediante, a quien en Francia llaman Papá Michel. Soy conocido en todas las cortes..." (CC, p. 697). En Arlequín, Colombina y Arlequín aparecen primero en escena: ella canta un romance burlesco de su novio, él comenta lo precioso de la voz de ella; al final, los dos alternan su propia canción sobre el amor ${ }^{50}$. El horroroso empieza con la introducción de Pepito Rubores en defensa de su obra contra lo que los críticos van a decir de ella. En el "Epílogo" los mismos críticos citados por Pepito en la introducción discuten la obra que acaban de ver. El "nocturno empieza en el convento del Salvador con una canción popular que encierra muchas claves del misterioso linaje de Beltrán ${ }^{51}$. La obra termina en el mismo con-

${ }^{50}$ He aquí las canciones de Colombina y Arlequín:

Anoche, el gato de casa,/ yo lo puse en el balcón,/ronda que ronda, el maldito,/ encontró mi corazón./ ¡Ay, chúmbala, que es calabaza,/ ay, chúmbala, que es polisón,/ ay, chúmbala, las chicas guapas/ y el peñuelo de crespón! -Colombina.

A la chica de esta casa/ le tengo que regalar/ un muñeco muy bonito/ para que pueda jugar./ ¡Ay, chúmbala, que es calabaza,/ ay, chúmbala, que es polisón,/ ay, chúmbala, que es caramelo,/ caramelo del Japón! —Arlequín (A, p. 687).

51 A continuación se ofrece la canción del señor Pepe: Cuando yo eztaba en prizionez,/ en lo que me entretenía:/ en contar los ezlabonez/ que mi cade- 
vento cuando Beltrán muere empezando a tocar su "nocturno". Tanto la canción popular como el "nocturno" se relacionan con la misteriosa vida del protagonista, de manera que las dos piezas musicales contrapuestas se complementan, explicando la vida de Beltrán. Sólo Todo acaba tiene un final abierto.

\section{CONCLUSIONES}

Baroja, como otros escritores coetáneos suyos que estaban seriamente comprometidos en combatir los abusos de un teatro español atrofiado, ve la necesidad de una renovación teatral en España. Las seis piezas teatrales ofrecidas por él son una respuesta a las exigencias del momento, esto es, rehacer el teatro. Buscan conferirle un espíritu popular y una voluntad iconoclasta frente a los cánones dramático-literarios.

Las tres obras escritas en 1926 hacen patente la naturaleza ficticia de la puesta en escena y convierten al pueblo en una fuente de inspiración. Con este propósito los "tipos" que forman el núcleo de los personajes de estas obras contrarrestan, si bien tardíamente, la frialdad que Baroja veía en los dramas que había criticado cuando escribía para $E l$ Globo. Su preferencia por el género chico, la canción popular y los "espectáculos" criminales del viejo Madrid de principios de siglo tienen su correlación con las dimensiones populares de su teatro. La falsa retórica y los fríos diálogos del teatro finisecular ejemplificado en las piezas de Echegaray fueron sustituidos por una representación escénica tan ficticia y, en muchas ocasiones, conocida (esto es, artificiosa) que no le quedaba al público otro remedio que darse cuenta de que lo que presenciaba en las tablas no era real ni verdadero, sino pura farsa. Se puede concluir, entonces, que Baroja, al escribir estas obras, nunca abandonó su filosofía personal frente al teatro: "A mí, al menos, toda esa teatralidad no me interesa ni me divierte nada. Encuentro mucho más interesante al hombre espontáneo, aunque sea un bruto y un tosco" ${ }^{52}$.

na tenía./.................. $\mathrm{Y}$ vinieron los frailes franciscanosi y lo conjuraron en un callejón./............. Tengo do lunare, / tengo do lunare:/ el uno junto a la frente, $/$ el otro tú zabez./................. ¡ $\mathrm{A}$ Ay, trizte marinería!/ ¡Ay trizte marinería!/ En la caza que tenía,/ mi ventana daba al mar,/ y lo que me entretenía/ al ver los barcos pazar/ de Bigraltar a Almería .../ ¡Ay trizte marinería!/ ................ Zan Pedro, como era calvo,/ le picaban los mozquitos,/ y su madre le desía:/ Ponte el gorro, Periquito/ (N, pp. 1177-1178).

52 "Primeros libros", op. cit., p. 436. 
A fin de cuentas, tanto se empeñó Baroja en su propia libertad de escritor que le costó la espontaneidad que buscaba en el teatro. La actitud burlona de los "Autores" que se dirigen al público es, asimismo, un desafío dirigido inequívocamente a los críticos de teatro profesionales. La estructura tan irregular de varias de las obras de Baroja aumenta la anarquía de su puesta en escena. La ironía de su falta de interés en "toda esa teatralidad" brota de la falsedad de las artificiales puestas en escena y la retórica de un teatro "oficial" que insistía en simular (y muy mal) la realidad en las tablas. Las incursiones teatrales de don Pío son, en suma, una jactancia de la ficción que es el teatro por naturaleza, una afirmación del espíritu de autonomía que tiene a su disposición todo escritor y una vuelta a la espontaneidad que debe motivar a cualquier representación teatral.

LuCile C. Charlebois

University of Nebraska-Lincoln 